\title{
Uptake and degradation of Curosurf $\circledast$ after tracheal administration to newborn and adult rabbits
}

\author{
A. Alberti*, A. Pettenazzo**, G.B. Enzi*, A. Palamidese***, C. Mapp****, \\ P. Ventura+, A. Baritussio*
}

Uptake and degradation of Curosurf $₫$ after tracheal administration to newborn and adult rabbits. A. Alberti, A. Pettenazzo, G.B. Enzi, A. Palamidese, C. Mapp, P. Ventura, A. Baritussio. CERS Journals Ltd 1998.

ABSTRACT: This paper examines the removal from the airways of Curosurf $\circledast$, a commercial surfactant derived from porcine lungs, administered at pharmacological concentrations to newborn or adult animals.

Curosurf was labelled by the addition of radioactive dipalmitoyl phosphatidylcholine (DPPC) and administered intratracheally to newborn and adult rabbits at a dose of $200 \mathrm{mg} \cdot \mathrm{kg}^{-1}$ body weight. The disappearance of DPPC from the airways and its appearance in alveolar macrophages, lung parenchyma, lamellar bodies, serum, liver, kidneys and brain was then studied for $24-48 \mathrm{~h}$. The in vitro degradation of Curosurf DPPC by alveolar macrophages was also studied.

During the first $3 \mathrm{~h}$ after instillation, large amounts of Curosurf left the airways and became associated with tissue, indicating that it mixed rapidly with the endogenous pools of surfactant. A fraction of administered DPPC became associated with the lamellar bodies, suggesting that Curosurf can be recycled. Curosurf administration did not stop the secretion of endogenous surfactant. Very little intact radioactive DPPC could be recovered at any time in alveolar macrophages, however, macrophages have the ability, in vitro, to degrade Curosurf. Newborn rabbits lose Curosurf from the lungs at a slower rate than adult rabbits. One and two days after instillation, organic extracts from the liver, kidney, brain and serum contained small but measurable amounts of radioactivity.

These results indicate that Curosurf rapidly enters the pathways of surfactant metabolism and that alveolar macrophages may play an important role in the catabolism of Curosurf.

Eur Respir J 1998; 12: 294-300.
Depts of *Internal Medicine, **Paediatrics, ***Pulmonology and ****Occupational Medicine, University of Padova, Padova, Italy. ${ }^{+}$Chiesi Farmaceutici, Parma, Italy.

Correspondence: A. Baritussio

Institute of Internal Medicine

University of Padova

Via Giustiniani 2

35100 Padova

Italy

Fax: 39498212151

Keywords: Alveolar macrophage

Curosurf®

surfactant turnover

tracheal instillation

Received: May 261997

Accepted after revision March 291998

This work has received generous support from The Centre of Aging Studies of Padova, Italy.
Different types of surfactant, either synthetic or derived from mammalian lungs, are currently utilized with excellent results in the treatment of immature infants affected by the respiratory distress syndrome (RDS) [1-3]. Exogenous surfactants have also been used to treat other lung disorders such as RDS in mature newborns and adult patients, the meconium aspiration syndrome and pneumonia [4-9]. Apart from its ability to lower surface tension, surfactant can also be used as a spreading agent [10-13].

Experiments performed by administering trace amounts of natural surfactant into the trachea indicate that soon after administration components of surfactant (both lipids and proteins) are taken up by alveolar type II cells, associated with the lamellar bodies and resecreted, while part of the material escapes recycling and is removed from the system [14-16]. Thus far, however, the mechanism that directs used components of surfactant towards reutilization or catabolism is poorly understood.

In previous studies it was found that labelled Surfactant TA (a surfactant derived from bovine lungs), administered into the trachea of premature and adult rabbits: 1) associates with the endogenous pools of surfactant soon after instillation; 2) remains in the lung for a long time; 3) does not change the endogenous synthesis of phosphatidylcho- line or its secretion, even when administered as a treatment dose; and 4) does not accumulate within alveolar macrophages [17-20]. These studies suggested that exogenous surfactant could be recycled and indicated that macrophages play a minor role in surfactant catabolism.

This view needs to be revised, since subsequent studies on the clearance of a nonmetabolizable analogue of dipalmitoylphosphatidylcholine (DPPC) [21] and calculations presented by WRIGHT and Youmans [22] suggest that alveolar macrophages could degrade important amounts of surfactant. Furthermore, it has been found that mice made deficient of the granulocyte macrophage colony-stimulating factor (GM-CSF) display a marked accumulation of surfactant in the airways [23, 24].

This paper reports studies on the removal from the airways of Curosurf®, a surfactant derived from porcine lungs, which has proved highly efficient in lowering surface tension in vitro, in preventing the development of RDS in animal models of lung immaturity and in the treatment of RDS in premature babies [3].

The aim was to describe the removal of pharmacological amounts of Curosurf administered by tracheal instillation to newborn and adult rabbits and to study the role of alveolar macrophages in the process of removal. Since 
DPPC associated with macrophages recovered by lung lavage may represent lipid aggregates adhering to the cell surface [25] and cannot be expected to reflect the rate of degradation, the ability of alveolar macrophages to degrade Curosurf DPPC was studied in vitro.

\section{Materials and methods}

\section{Preparation of labelled Curosurf}

Labelled Curosurf was prepared by Chiesi Farmaceutici (Parma, Italy) by mixing radioactive DPPC with extracts of pig surfactant. The mixture was then dried, suspended in saline and sonicated.

For in vivo studies Curosurf was labelled with 1-3-phosphatidyl[ $N$-methyl-14 $\mathrm{C}]$ choline,1,2-dipalmitoyl ([14C]DPPC) (Amersham, Bucks, UK; specific activity $56 \mathrm{mCi} \cdot \mathrm{mmol}^{-1}$ ). The final suspension in saline $\left(80 \mathrm{mg} \cdot \mathrm{mL}^{-1}\right)$ contained either 0.04 or $0.4 \mu \mathrm{Ci} \cdot \mu \mathrm{mol}^{-1}$. Labelled Curosurf was tested for surface activity both by the pulsating bubble method [26] and by proving its ability to rescue mechanically ventilated immature rabbits [27].

For in vitro studies Curosurf was labelled with 1-3- phosphatidyl[ $N$-methyl-3 $\left.{ }^{3} \mathrm{H}\right]$ choline,1,2-dipalmitoyl $\left(\left[{ }^{3} \mathrm{H}\right]\right.$ DPPC) (DuPont NEN, Boston, MA, USA; specific activity 40 $\left.\mathrm{Ci} \cdot \mathrm{mmol}^{-1}\right)$. The final suspension in saline $\left(80 \mathrm{mg} \cdot \mathrm{mL}^{-1}\right)$ contained $0.4 \mu \mathrm{Ci} \cdot \mu_{\mathrm{mol}}^{-1}$ DPPC. The purity of the labelled DPPCs was tested before use by thin-layer chromatography [28].

\section{Curosurf clearance studies in adult rabbits}

Female rabbits (body weight $1.7 \pm 0.1 \mathrm{~kg})($ mean $\pm \mathrm{SE})$ were anaesthesized with a $10 \mathrm{mg}$ bolus of sodium thiopental i.v., followed by the infusion of sufficient thiopental solution $\left(5 \mathrm{mg} \cdot \mathrm{mL}^{-1}\right)$ to abolish the corneal reflex. After local anaesthesia with $2 \%$ lidocaine, the trachea was ex-posed and an $18 \mathrm{G}$ needle was inserted immediately below the cricoid cartilage. A small catheter was then introduced through the needle and advanced so that the tip was located $2 \mathrm{~cm}$ above the carina. Curosurf $\left(200 \mathrm{mg} \cdot \mathrm{kg}^{-1}, 0.04\right.$ $\left.\mu \mathrm{Ci} \cdot \mu \mathrm{mol}^{-1} \mathrm{DPPC}\right)$ was then instilled while the thorax, previously compressed, was expanded. The catheter was removed and the rabbit, lifted in an upside-down position, was stimulated to breathe. No loss of material was detected either through the trachea or from the upper airways. The small incision was then sutured and the animal was placed in a warm cage and left to recover. The average duration of the procedure was $10 \mathrm{~min}$.

Rabbits were divided into groups of four. One group was killed immediately with an excess of thiopental i.v., whereas the other groups were killed after 1, 3, 8 and $24 \mathrm{~h}$. The trachea was then cannulated and lung lavage was performed with $0.9 \%$ saline at room temperature. The lungs were visually filled and the saline was washed in and out of the lungs three times and recovered. This washing procedure was repeated four more times for each animal and the five washes were pooled and brought to a volume of $400 \mathrm{~mL}$ with saline [17]. More than $95 \%$ of instilled fluid was usually recovered. The lavaged lungs were minced and homogenized at $4{ }^{\circ} \mathrm{C}$ in saline. To isolate alveolar macro- phages, $30 \mathrm{~mL}$ of lavage fluid was centrifuged at $1000 \mathrm{~g}$ for $20 \mathrm{~min}$ over a cushion of $0.7 \mathrm{M}$ sucrose in saline. The pellet, containing over $90 \%$ alveolar macrophages, was suspended in $2 \mathrm{~mL}$ saline. Samples were stored at $-20^{\circ} \mathrm{C}$ until used for analysis.

Cells on the lavage fluid were counted after staining with crystal violet, proteins were measured using bovine albumin as the standard [29], lactate dehydrogenase (LDH) activity was measured using a commercial kit (Boehringer Mannheim, Germany) and lipid phosphorus was measured using the Bartlett procedure [30] after extraction according to BLIGH and DYER [31]. From aliquots of Bligh and Dyer extracts, DPPC was isolated using the method of MASON et al. [32]. Part of the DPPC was then used for assay of phosphorus and part for radioactivity counting. Radioactivity was measured using a dioxane-based scintillant and quenching was estimated with the channels ratio, using a set of quenched standards generated in our laboratory. DPPC was also isolated from lung homogenate and from alveolar macrophages and the associated radioactivity was estimated. In all experiments the recovery of administered Curosurf was expressed as a percentage of the radioactivity present in lavage fluid plus lung homogenate at time zero.

\section{Curosurf clearance studies in 3-day-old rabbits}

To investigate the clearance from the lungs, 30 rabbits received, into the trachea, Curosurf with a specific activity of $0.04 \mu \mathrm{Ci} \cdot \mu \mathrm{mol}^{-1} \mathrm{DPPC}$ and a concentration of $80 \mathrm{mg}$ phospholipids $\cdot \mathrm{mL}^{-1}$. To detect radioactivity in organs other than the lungs, 18 rabbits received Curosurf with a specific activity of $0.4 \mu \mathrm{Ci} \cdot \mu \mathrm{mol}^{-1} \mathrm{DPPC}$ and a concentration of $80 \mathrm{mg}$ phospholipids $\cdot \mathrm{mL}^{-1}$. Each rabbit received 200 mg surfactant $\cdot \mathrm{kg}^{-1}$. The body weight was $101 \pm 4 \mathrm{~g}$.

To administer Curosurf the trachea was exposed under local anaesthesia with $2 \%$ lidocaine and Curosurf was instilled through a bent $25 \mathrm{G}$ needle inserted just below the cricoid cartilage. During the injection the trachea proximal to the injection point was gently compressed and the chest, previously compressed, was released. After the injection the animal was rapidly tilted to an upside-down position and allowed to breathe spontaneously. The small incision was closed with a suture. Two rabbits that had a clear loss of material immediately after administration were discarded prospectively.

Animals used in the study of lung clearance mechanisms were killed in groups of five after $0,1,3,8$ and 24 $\mathrm{h}$. The trachea was then cannulated and the lungs were lavaged, using $4-5 \mathrm{~mL}$ of $0.9 \%$ saline infused to distend the lungs fully and withdrawn repetitively three times. This procedure was repeated with four more saline volumes and the five washes were pooled and brought to 25 $\mathrm{mL}$ with saline [19]. Usually, 92 $\pm 4 \%$ ( $\pm \mathrm{SD}$ ) of the instilled fluid was recovered. No rabbit had to be discarded for fluid leaks or because the lavage fluid was macroscopically contaminated with blood. An aliquot of the lavage fluid was used for the isolation of macrophages. Lavage fluid, lung homogenate and alveolar macrophages were treated exactly as described for adult animals. Animals used in the study of the distribution of Curosurf components outside the lung were killed in groups of six after 0 , 24 and $48 \mathrm{~h}$, blood was collected and lungs, liver, kidneys 
and brain were homogenized. Serum and homogenates were then extracted according to BLIGH and DYER [31] and the radioactivity of the organic phase was measured. To calculate the volume of total serum the haematocrit was measured and a blood volume of $80 \mathrm{~mL} \cdot \mathrm{kg}^{-1}$ was assumed.

\section{Association of Curosurf with lamellar bodies}

To study the association of Curosurf with lamellar bodies, labelled Curosurf (200 mg. $\mathrm{kg}^{-1}$, specific activity 0.04 $\left.\mu \mathrm{Ci} \cdot \mu \mathrm{mol}^{-1} \mathrm{DPPC}\right)$ was instilled into the trachea of sixteen 3 -day-old rabbits. They were killed in groups of four after $3,12,24$ and $48 \mathrm{~h}$, lamellar bodies were isolated (density 1.04-1.08 $\left.\mathrm{g} \cdot \mathrm{mL}^{-1}\right)$ [33] and the radioactivity associated with lamellar body DPPC was then measured.

\section{Degradation of Curosurf by alveolar macrophages}

Alveolar macrophages were obtained by centrifugation of lung lavage fluid collected from $1 \mathrm{~kg}$ rabbits exactly as described by PIson et al. [34]. The macrophage pellet, containing $>90 \%$ macrophages (viability $>95 \%$ ), was washed two times with Dulbecco's modified Eagle medium (DMEM, Gibco, Paisley, UK) containing $2 \mathrm{mM}$ glutamine, $3 \mathrm{~g}$ glucose and $3.7 \mathrm{~g} \mathrm{Na}_{2} \mathrm{HCO}_{3}$ per litre and was brought to a concentration of 250,000 cells $\cdot \mathrm{mL}^{-1}$. Aliquots $(2 \mathrm{~mL})$ of this suspension were then applied to three wells of 6-well Falcon plates and the cells were allowed to adhere to plastics for $3 \mathrm{~h}$ at $37^{\circ} \mathrm{C}$ in an atmosphere of $5 \% \mathrm{CO}_{2}$. The remaining three wells were used to measure the spontaneous degradation of substrate (blank wells). After $3 \mathrm{~h}$ wells containing adhering macrophages and blank wells were added with $2 \mathrm{~mL}$ of DMEM containing $10 \%$ lipoprotein-poor foetal calf serum, 5,000 U. $\mathrm{mL}^{-1}$ penicillin, 5,000 $\mu \mathrm{g} \cdot \mathrm{mL}^{-1}$ streptomycin and $0.1-32$ $\mathrm{mg}$ labelled Curosurf and incubated at $37^{\circ} \mathrm{C}$ for $1-16 \mathrm{~h}$. At the end the content of the wells was recovered using a cell scraper, homogenized at $4^{\circ} \mathrm{C}$ and extracted according to BLIGH and Dyer [31] in the presence of $0.2 \mathrm{mg}$ rabbit surfactant (carrier).

The degradation of Curosurf by alveolar macrophages was estimated by measuring the generation of radioactive products partitioning in the water/methanol phase during the extraction. Since, under the conditions chosen, macrophages degrade less than $1 \%$ of substrate, the water/methanol phase was washed with $3 \mathrm{~mL}$ synthetic chloroform phase before counting. The radioactivity of $1 \mathrm{~mL}$ of the water/methanol phase was then counted in the presence of $10 \mathrm{~mL}$ of Hyonic fluor (Packard, Groningen, The Netherlands). To calculate the degradation of DPPC by macrophages the spontaneous degradation of labelled DPPC was subtracted. The assays were done in duplicate or triplicate and the results are expressed as ng DPPC degraded $10^{-6}$ cells $\cdot \mathrm{h}^{-1}$.

\section{Data presentation}

Data are expressed as mean \pm SE. Differences between groups were tested by analysis of variance (ANOVA) and significance was assessed by the Scheffé procedure. The level of significance accepted was $5 \%$.

\section{Results}

\section{Adult animals}

In rabbits killed immediately after tracheal instillation, $100 \pm 1 \%$ of administered Curosurf was recovered, $85 \%$ of which was associated with the lavage fluid and $15 \%$ with lung homogenate (fig. 1). During the first $3 \mathrm{~h}$, in spite of a negligible loss from the lungs, there was a dramatic change in the distribution of label between lavage fluid and lung parenchyma, with most of the label becoming associated with the parenchyma. After the $3 \mathrm{~h}$, however, the label left the airways and parenchyma at a comparable speed. From the regression line drawn through the total lung recovery of labelled DPPC it appears that the average loss was $1.9 \% \cdot \mathrm{h}^{-1}(\mathrm{r}=0.92, \mathrm{p}<0.001)$, corresponding to a half-life of $\sim 26 \mathrm{~h}$.

During the day that followed instillation radioactivity associated with the cells of lavage was never greater than $3 \%$ of the administered dose and there was no discernible pattern of change with time (fig. 1).

The alveolar pool of DPPC, which was greatly increased by Curosurf administration, decreased over time but, after $24 \mathrm{~h}$, was still greater than normal (fig. 2). The specific activity of lavage DPPC also decreased over time (fig. 2), indicating that unlabelled DPPC continued to be secreted into the alveoli. The specific activity of alveolar DPPC would have remained constant if administered Curosurf had stopped the secretion of endogenous (unlabelled) surfactant.

The number of cells recovered by lavage did not change significantly during the experiment and the specific activity of cell DPPC was at all times similar to that of lavage DPPC (data not shown). In lung lavage fluid the protein concentration remained within normal limits and LDH activity was always at the lower limit of detection.

\section{Three-day-old rabbits}

In rabbits killed immediately after instillation, $96 \pm 1 \%$ of administered Curosurf was recovered, $76 \%$ of which was

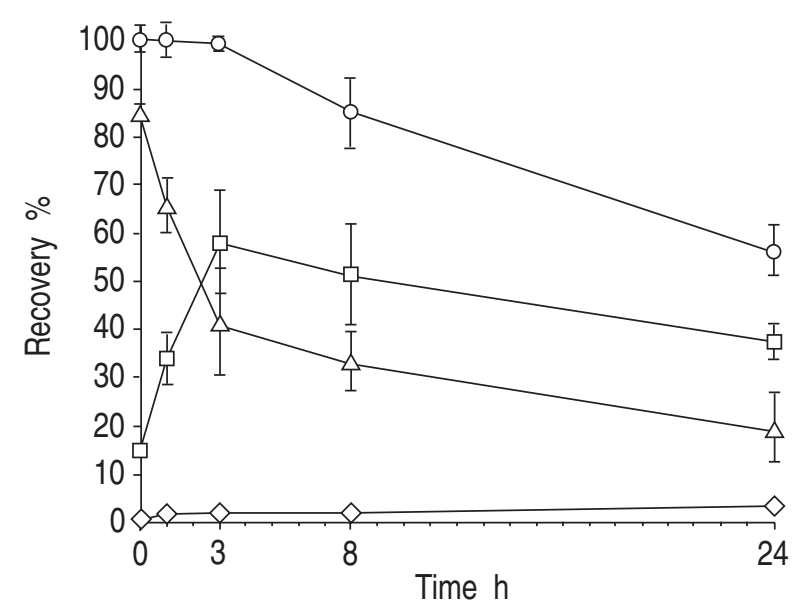

Fig. 1. - Percentage recovery of $\left[{ }^{3} \mathrm{H}\right]$ dipalmitoylphosphatidylcholine (DPPC) from total lung $(O)$, alveolar washes $(\Delta)$, lung homogenate $(\square)$ and alveolar macrophages $(\diamond)$ after tracheal administration of labelled Curosurf to adult rabbits (200 $\left.\mathrm{mg} \cdot \mathrm{kg}^{-1}, 0.04 \mu \mathrm{Ci} \cdot \mu \mathrm{mol}^{-1} \mathrm{DPPC}\right)$. Values are mean \pm SEM for four rabbits per time point. 

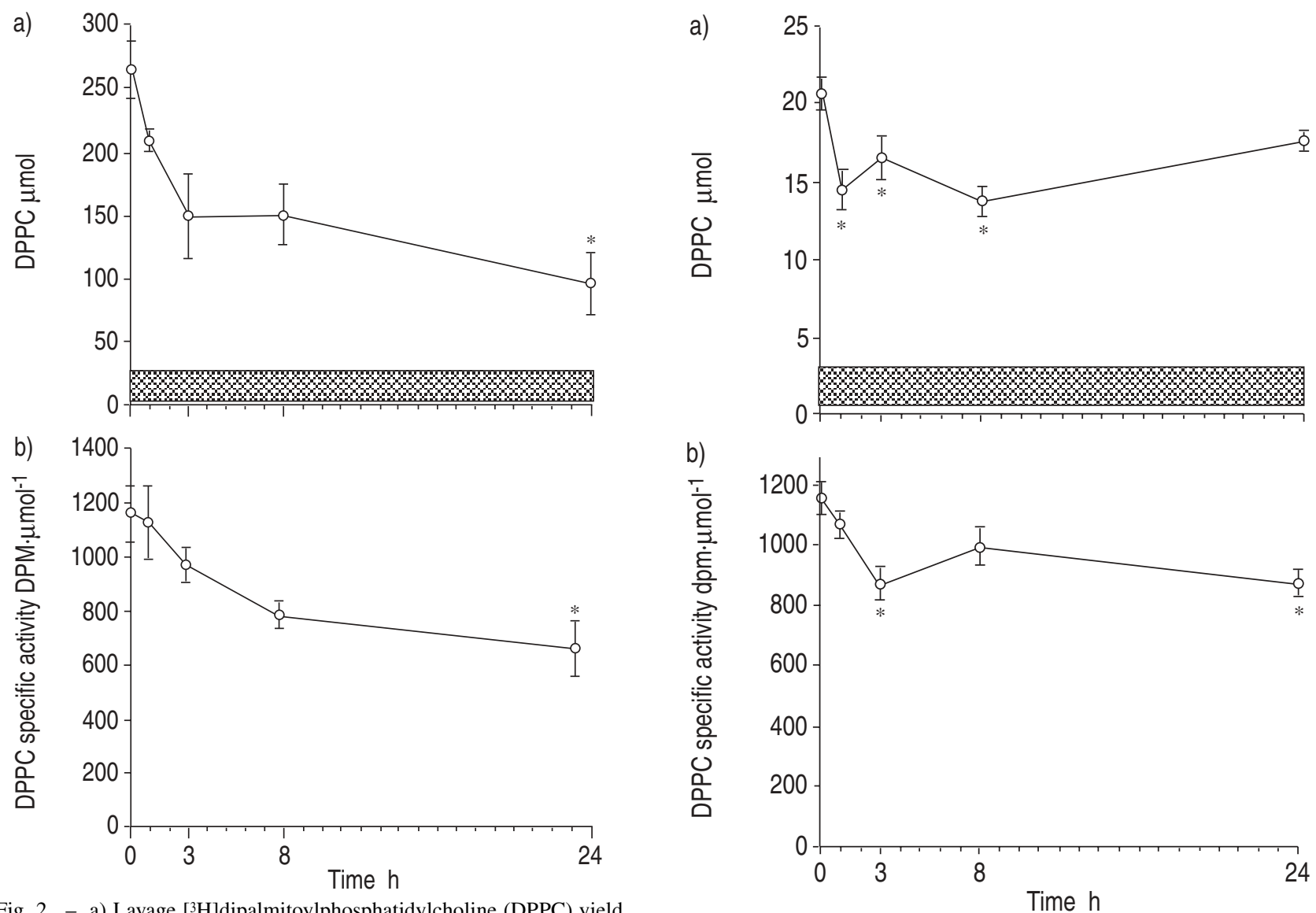

Fig. 2. - a) Lavage [ $\left.{ }^{3} \mathrm{H}\right]$ dipalmitoylphosphatidylcholine (DPPC) yield and b) specific activity after tracheal administration of labelled Curosurf to adult rabbits. Values are mean \pm sEM. The shaded area represents mean \pm 2 SD of DPPC alveolar pool in 10 adult rabbits of comparable body weight. dpm: disintegrations per minute. *: smaller than at time 0 $(\mathrm{p}<0.05$ by analysis of variance $)$.

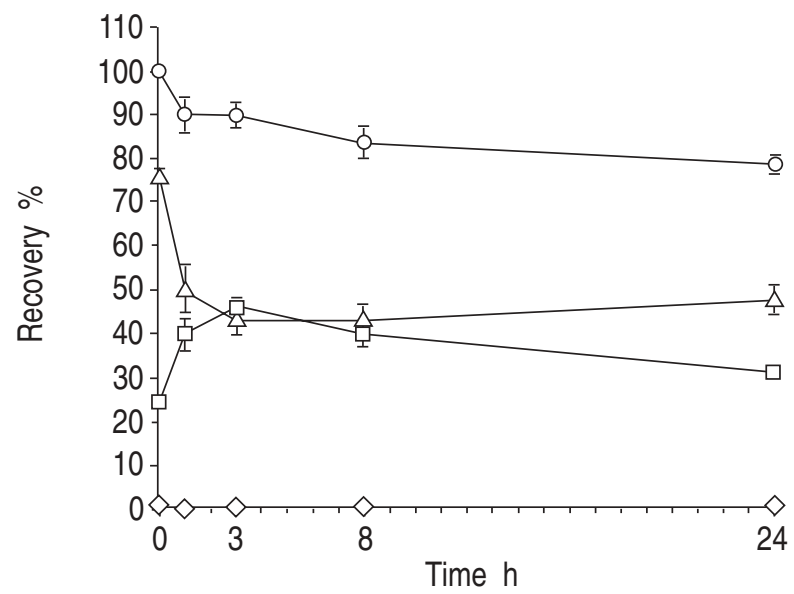

Fig. 3. - Percentage recovery of $\left[{ }^{3} \mathrm{H}\right]$ dipalmitoylphosphatidylcholine (DPPC) from total lung (O), alveolar washes $(\Delta)$, lung homogenate ( $\square$ ) and alveolar macrophages $(\vartheta)$ after tracheal administration of labelled Curosurf to 3 -day-old rabbits (200 $\mathrm{mg} \cdot \mathrm{kg}^{-1}, 0.04 \mu \mathrm{Ci} \cdot \mu \mathrm{mol}^{-1} \mathrm{DPPC}$ ). Values are mean \pm sem for five or six rabbits per time point.

associated with lavage fluid and $24 \%$ with lung parenchyma (fig. 3).

As observed in adult animals, during the first $3 \mathrm{~h}$ there was an abrupt change in the distribution of label between lavage fluid and lung homogenate, with a significant amount of label becoming associated with the homogenate (fig. 3).

Fig. 4. - a) Lavage $\left[{ }^{3} \mathrm{H}\right]$ dipalmitoylphosphatidylcholine (DPPC) yield and b) specific activity after tracheal administration of labelled Curosurf to 3-day-old rabbits. Values are mean \pm SEM. The shaded area represents mean \pm 2SD of DPPC alveolar pool in 10 3-day-old rabbits. dpm: disintegrations per minute. *: smaller than at time $0(\mathrm{p}<0.05$ by analysis of variance).

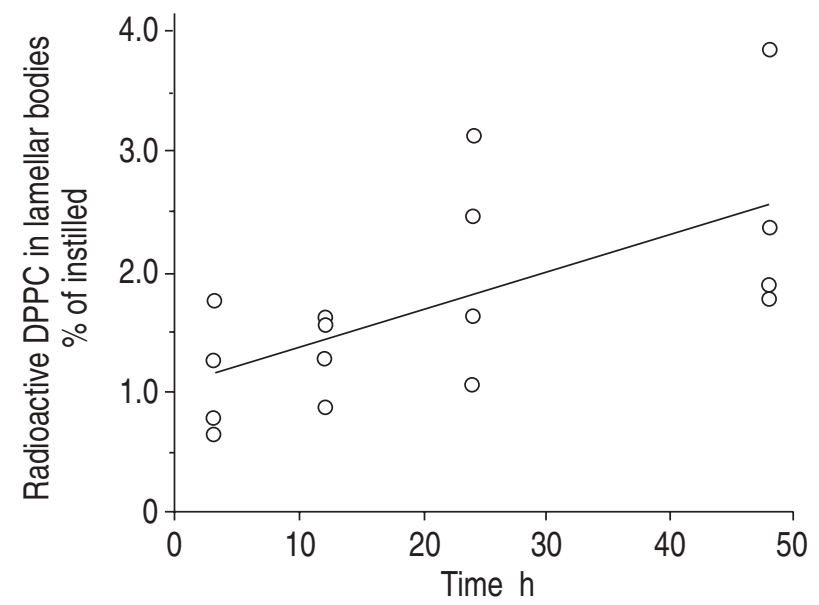

Fig. 5. - Association of Curosurf $\left[{ }^{3} \mathrm{H}\right]$ dipalmitoylphosphatidylcholine (DPPC) with lamellar bodies. Three-day-old rabbits received labelled Curosurf (200 mg.kg-1, $0.04 \mu \mathrm{Ci} \cdot \mathrm{mol}^{-1} \mathrm{DPPC}$ ) into the trachea and radioactive DPPC associated with the lamellar bodies was measured after 3-48 h. Data are presented as a percentage instilled radioactive DPPC. $\mathrm{r}=0.63, \mathrm{p}<0.01$.

In newborn rabbits the clearance of Curosurf from the lungs was slower than in adult animals. At $24 \mathrm{~h}$ newborns retained $79 \pm 2 \%$ of administered Curosurf, while adult rabbits retained $56 \pm 5 \%$. Furthermore, in newborns the loss of DPPC from the lung was $0.7 \% \cdot \mathrm{h}^{-1}(\mathrm{r}=0.66, \mathrm{p}<0.001$, 
Table 1. - Distribution of radioactive lipids after tracheal administration of labelled Curosurf to 3-day-old rabbits

\begin{tabular}{lrcccc}
\hline $\begin{array}{l}\text { Time } \\
\mathrm{h}\end{array}$ & Lungs & Liver & Kidneys & Brain & Serum \\
\hline 0 & $100 \pm 3$ & $0.0 \pm 0.0$ & $0.0 \pm 0.0$ & $0.0 \pm 0.0$ & $\operatorname{tr}$ \\
24 & $94 \pm 4$ & $0.3 \pm 0.1$ & $0.3 \pm 0.0$ & $0.2 \pm 0.0$ & $0.2 \pm 0.0$ \\
48 & $74 \pm 5$ & $0.5 \pm 0.1$ & $0.5 \pm 0.1$ & $0.5 \pm 0.1$ & $0.3 \pm 0.0$ \\
\hline
\end{tabular}

Values are shown as mean \pm Sem for five or six rabbits per time point. Values are the percentage of instilled radioactivity. tr: traces.
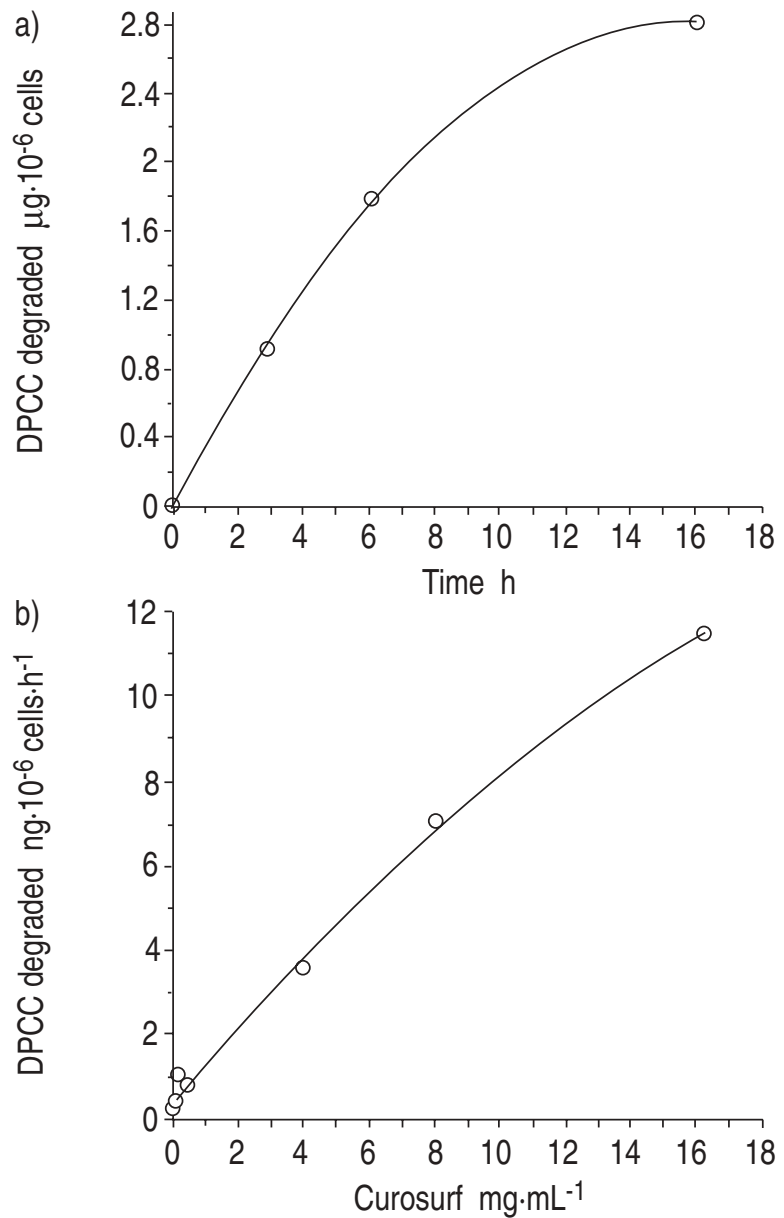

Fig. 6. - Degradation of $\left[{ }^{3} \mathrm{H}\right]$ dipalmitoylphosphatidylcholine (DPPC) in Curosurf by alveolar macrophages. Rabbit alveolar macrophages $\left(2.5 \times 10^{5}\right.$ cells.well-1) were incubated from a) $0-16 \mathrm{~h}$ at $37^{\circ} \mathrm{C}$ in the presence of $50 \mu \mathrm{g}$ Curosurf. $\mathrm{mL}^{-1}$ or b) $16 \mathrm{~h}$ in the presence of increasing concentrations of Curosurf. Data are representative of three experiments. Assays were carried out in duplicate. Curves were drawn by polynomial regression.

half-life $75 \mathrm{~h}$ ), a value significantly smaller than in adult rabbits $(\mathrm{p}<0.001)$. Finally, in newborn rabbits the alveolar pool of DPPC, greatly increased by Curosurf administration, decreased modestly over time in comparison with adult rabbits (fig. 4). It was also noticed that in newborn rabbits the specific activity of lavage DPPC changed less than in adult rabbits, suggesting that in newborns administered Curosurf was either turned over at a lower speed or recycled with a greater efficiency than in adults (compare figs. 2 and 4). Instilled Curosurf can be recycled, as indicated by the finding that radioactive DPPC associated with the lamellar bodies increased with time after instilla- tion (fig. 5). At any time the lamellar bodies contained a small fraction of instilled Curosurf, but the extent of recovery of these organelles under the present experimental conditions is unknown.

The number of cells recovered by lavage remained constant and the radioactive DPPC associated with them did not change over time, always being $<0.5 \%$ of the dose (fig. 3). The specific activity of macrophage DPPC was at all times similar to that of lavage DPPC (data not shown). Protein concentration and LDH activity measured in lavage fluid remained within normal limits during the experiment.

After tracheal instillation of Curosurf small, but measurable amounts of radioactivity could be detected outside the lungs (table 1). In all organs examined the lipid fraction contained, at maximum, $0.6 \%$ of the radioactivity present in the lungs at time zero.

\section{Studies in vitro}

Alveolar macrophages obtained from adult rabbits were able to degrade Curosurf DPPC in a time- and concentration-dependent manner (fig. 6). From the generation of water-soluble byproducts, in the presence of $50 \mu \mathrm{g}$ Curosurf. $\mathrm{mL}^{-1}$, we estimate that alveolar macrophages can degrade Curosurf DPPC at a rate of $153 \pm 34 \mathrm{ng}$ DPPC $\cdot \mathrm{h}^{-1} 10^{-6}$ cells $(n=4)$.

\section{Discussion}

In this study $200 \mathrm{mg}$ Curosurf $\cdot \mathrm{kg}^{-1}$ was administered through the trachea, with very small losses. This dose exceeds several times the alveolar pool of surfactant (figs. 2 and 4) and is justified on clinical grounds by the need to provide an excess of surfactant to surfactant-deficient patients, by the desire to overcome surfactant inhibitors or as a means to deliver drugs or genes to the terminal airways.

As found in other studies, $15-25 \%$ of administered Curosurf became associated to the lung immediately after instillation and could not be recovered by lavage [18]. This phenomenon remains to be explained and possibly reflects a specific interaction between surfactant components and lung cells, since it is not observed when liposomes made of pure surfactant lipids are administered through the airways [18].

After $3 \mathrm{~h}$ the label was lost from lavage fluid and homogenate at a much slower rate than during the first 3 h. This behaviour suggests that Curosurf rapidly enters the pathways by which surfactant is transported from the alveolar spaces to lung tissue. Curosurf did not stop the synthesis of endogenous (unlabelled) phosphatidylcholine and its secretion in the alveoli, since the specific activity of alveolar DPPC decreased over time. This finding is in agreement with data obtained with Surfactant TA in adult rabbits [20] and conforms to the results of a very recent experiment by BouRBon et al. [35] who showed that both surfactant phospholipids and Curosurf enhance the rate of phosphatidylcholine synthesis by isolated type II cells.

Curosurf DPPC enters the lamellar body compartment and thus appears to be recycled. The present data do not allow the extent of recycling to be estimated precisely, but it could have been important. Considering adult rabbits 
and assuming the amount of labelled DPPC present in the alveoli at time 0 to be $100 \%$, one can see that alveolarlabelled DPPC dropped at a fast rate during the first $3 \mathrm{~h}$, and at a slower rate thereafter. From the drop in radioactivity measured between 3 and $24 \mathrm{~h}$, taking into account the dilution of Curosurf DPPC by endogenous DPPC that continued to be secreted in the alveoli, the rate constant of disappearance of DPPC from the alveoli from 3 to $24 \mathrm{~h}$ was calculated to be $5.1 \% \cdot \mathrm{h}^{-1}$. This value contrasts sharply with the loss of labelled DPPC from the alveoli measured during the first hour $(-22.6 \pm 6.1 \%)$, indicating that a large fraction of the material taken up by the lung tissue must have been recycled to the alveoli. From inspection of the data this conclusion also seems to be valid for newborn rabbits. This reasoning, however, can be applied only if administered Curosurf is cleared exclusively by mechanisms utilized in surfactant turnover. For example, this interpretation is not valid if the rapid initial loss from the alveoli is due to the filling of tissue pools not involved in the turnover of ordinary surfactant.

Adult rabbits appear to clear Curosurf from the lung at a faster rate than newborns. The reason for this age-related discrepancy is unclear. It could be due to differences in the rate of turnover in the alveoli or removal from the lungs, to a difference in the efficiency of recycling (as indicated by this study and previous experiments) or a combination of these mechanisms. On the whole, the kinetic behaviour of Curosurf DPPC, which is characterized by rapid turnover in the alveoli, recycling between alveoli and parenchyma and slow removal from the lung, is similar to that of DPPC present in natural surfactant $[17,19]$.

The site of the terminal catabolism of Curosurf remains to be precisely defined; however, the evidence presented in this paper suggests that alveolar macrophages do not behave as idle bystanders, but may play an important role in the clearance of Curosurf. In vivo alveolar macrophages contained at any time a small fraction of administered DPPC, but were able in vitro to degrade it. In vitro the rate of degradation was dependent on both time and concentration and it was not possible to saturate the degradative system with concentrations close to those expected in the airways after administration of Curosurf. In the presence of $50 \mu \mathrm{g}$ Curosurf $\cdot \mathrm{mL}^{-1}$, macrophages were able to degrade $153 \pm 34 \mathrm{ng}$ DPPC $\cdot 10^{-6}$ cells $\cdot \mathrm{h}^{-1}$. This estimate is comparable to the value ( $270 \mathrm{ng}$ DPPC degraded $\cdot 10^{-6}$ cells $\cdot \mathrm{h}^{-1}$ ) obtained by Wright and Youmans [22] by exposing rat alveolar macrophages to liposomes $\left(80 \mu \mathrm{g}\right.$ phospholipids $\left.\cdot \mathrm{mL}^{-1}\right)$ containing DPPC labelled on the palmitic acid in position 2. Considering that the concentration of phospholipids in the alveolar spaces was very high after Curosurf administration (possibly tens of milligrams $\cdot \mathrm{mL}^{-1}$ at the start of the experiment) and that adult rabbits had $49 \pm 7 \times 10^{6}$ cells in lavage, it was calculated that alveolar macrophages could have degraded a significant fraction of administered Curosurf. For example, if the concentration of Curosurf in the alveolar spaces were $10 \mathrm{mg}$ phospholipids $\cdot \mathrm{mL}^{-1}$, the degradation would have been $153 \mathrm{ng}$ DPPC $\times(10 / 0.05) \times 49$ $\times 24=36 \mathrm{mg}$ DPPC $\cdot$ day $^{-1}$. This value re-presents an important fraction of Curosurf lost from the lungs of adult rabbits in $24 \mathrm{~h}(162 \mathrm{mg})$ and indicates that alveolar macrophages may represent a major pathway of removal of Curosurf. The ability to take up Curosurf could make alveolar macrophages a target for the tracheal ad-ministra- tion of Curosurf associated with drugs active ag-ainst intracellular infectious agents.

One and two days after instillation, organic extracts from liver, kidney, brain and serum contained small but measurable amounts of radioactivity, indicating that, after use in the lung, Curosurf components are utilized by other organs.

On the basis of protein concentration and LDH activity in lavage fluid it appears that the animals tolerated Curosurf administration very well. The fact that the endogenous secretion of surfactant did not stop after Curosurf administration may also suggest that Curosurf did not interrupt vital aspects of lung surfactant metabolism.

To summarize, after tracheal administration Curosurf rapidly enters the pathways of surfactant metabolism and stays in the lung for a long time. After degradation, Curosurf byproducts are utilized by other body organs. Alveolar macrophages may play an important role in the catabolism of Curosurf.

Acknowledgements: The authors thank M. Digito for
help with macrophage isolation.

\section{References}

1. Poulain FR, Clements JA. Pulmonary surfactant therapy. West J Med 1995; 162: 43-50.

2. Robertson B. Surfactant replacement and neonatal pathology. In: Askin FB, Langston C, Rosemberg HS, Bernstein J, eds. Pulmonary Disease. Perspectives in Pediatric Pathology, Vol. 18. Basal, Karger, 1995; pp. 5-31.

3. Wiseman LR, Bryson HM. Porcine-derived surfactant. A review of the therapeutic efficacy and clinical tolerability of a natural surfactant preparation (Curosurf) in neonatal respiratory distress syndrome. Drugs 1994; 48: 386-403.

4. Diniz EMA, Fiori RM. Curosurf therapy in severe meconium aspiration syndrome. Biol Neonate 1995; 67: Suppl. 1,86 .

5. Findlay RD, Taeusch HW, Walther FJ. Surfactant replacement therapy for meconium aspiration syndrome. Pediatrics 1996; 97: 48-52.

6. Halliday HL, Speer CP, Robertson B. Treatment of severe meconium aspiration syndrome with porcine surfactant. Eur J Pediatr 1996; 155: 1047-1051.

7. Harms K, Herting E. Successful surfactant replacement therapy in two infants with ARDS due to clamydial pneumonia. Respiration 1994; 61: 348-352.

8. Marraro G. Use of surfactant in adult respiratory distress syndrome. J Anaesth Clin Pharmacol 1996; 11: 275-278.

9. Spragg RG, Gilliard N, Richman P, et al. Acute effects of single dose administration of the hydrophobic components of porcine surfactant to patients with the adult respiratory distress syndrome. Chest 1994; 105: 195-202.

10. Espinosa FF, Shapiro AH, Fredberg JJ, Kamm RD. Spreading of exogenous surfactant in an airway. $J$ Appl Physiol 1993; 75: 2028-2039.

11. Gilliard N, Richman PM, Merrit TA, Spragg RG. Effect of volume and dose on the pulmonary distribution of exogenous surfactant administered to normal rabbits or to rabbits with oleic acid injury. Am Rev Respir Dis 1990; 141: 743-747.

12. Jobe AH, Ueda T, Whitsett JA, Trapnell BC, Ikegami M. Surfactant enhances adenovirus-mediated gene expression in rabbit lungs. Gene Therapy 1996; 3: 775-779. 
13. Karasch VS. Pulmonary surfactant as a vehicle for tracheal delivery of technetium sulfur and pentamidine to hamster lungs. Am Rev Respir Dis 1991; 144: 909-913.

14. Baritussio A, Pettenazzo A, Benevento M, Alberti A, Gamba P. Surfactant protein C is recycled from the alveoli to the lamellar bodies. Am J Physiol 1992; 263 (Lung Cell Mol Physiol 7): L607-L611.

15. Ueda TA, Ikegami M, Henry M, Jobe AH. Clearance of surfactant protein B from rabbit lungs. Am J Physiol 1995; 268 (Lung Cell Mol Physiol 12): L636-L641.

16. Young SL, Wright JR, Clements JA. Cellular uptake of surfactant lipids and apoprotein SP-A by rat lung. $J$ Appl Physiol 1989; 66: 1336-1342.

17. Pettenazzo A, Ikegami M, Seidner S, Jobe A. Clearance of surfactant phosphatidylcholine from adult rabbit lungs. J Appl Physiol 1988; 64: 120-127.

18. Pettenazzo A, Jobe AH, Ikegami M, Seidner S. Clearance of treatment doses of surfactant. Effect of lipid extraction and aggregate size. Biol Neonate 1988; 53: 23-31.

19. Pettenazzo A, Oguchi K, Seidner S, Ikegami M, Berry D, Jobe A. Clearance of natural surfactant phosphatidylcholine from 3-day-old rabbit lungs: effect of dose and species. Pediatr Res 1986; 20: 1139-1142.

20. Seidner SR, Jobe AH, Ruffini L, Ikegami M, Pettenazzo A. Recovery of treatment doses of surfactants from the lungs and vascular compartment of mechanically ventilated premature rabbits. Pediatr Res 1989; 25: 423-428.

21. Rider ED, Ikegami M, Jobe AH. Localization of surfactant clearance in rabbit lung cells. Am J Physiol 1992; 263 (Lung Cell Mol Physiol 7): L201-L209.

22. Wright JR, Youmans DC. Degradation of surfactant lipids and surfactant protein A by alveolar macrophages in vitro. Am J Physiol 1995; 268 (Lung Cell Mol Physiol 268): L772-L780.

23. Dranoff G, Crawford AD, Sadelain M, et al. Involvement of granulocyte-macrophage colony-stimulating factor in pulmonary homeostasis. Science 1994; 264: 713-716.

24. Stanley EG, Lieschke GJ, Grail D, et al. Granulocyte/ macrophage colony-stimulating factor deficient mice show no major perturbation of hematopoiesis but develop a characteristic pulmonary pathology. Proc Natl Acad Sci USA 1994; 91: 5592-5596.

25. Horowitz AD, Moussavian B, Whitsett JA. Roles of SPA, SP-B and SP-C in modulation of lipid uptake by pulmonary epithelial cells in vitro. Am J Physiol 1996; 270 (Lung Cell Mol Physiol): L69-L79.

26. Enhorning G. Pulsating bubble technique for evaluating pulmonary surfactant. J Appl Physiol 1977; 43: 198-203.

27. Lachmann B, Grossmann G, Nilsson R, Robertson B. Effect of supplementary surfactant on in vivo lung mechanics in the premature rabbit neonate. Eur J Pediatr 1981; 136: 173-179.

28. Poorthuis BJHM, Yazaki PJ, Hostetler KY. An improved thin-layer chromatography system for the separation of phosphatidylglycerol and its derivatives. J Lipid Res 1976; 17: 433-437.

29. Polacheck I, Cabib E. A simple procedure for protein determination by the Lowry method in dilute solutions and in the presence of interfering substances. Anal Biochem 1981; 117: 311-314.

30. Bartlett GR. Phosphorus assay in column chromatography. J Biol Chem 1959; 234: 466-468.

31. Bligh EG, Dyer WJ. A rapid method of total lipid extraction and purification. Can J Biochem Physiol 1959; 37: 911-917.

32. Mason RJ, Nellenbogen J, Clements JA. Isolation of disaturated phosphatidylcholine with osmium tetroxide. $J$ Lipid Res 1976; 21: 281-284.

33. Baritussio A, Magoon MW, Goerke J, Clements JA. Precursor-product relationship between rabbit Type II cell lamellar bodies and alveolar surface active material: surfactant turnover time. Biochim Biophys Acta 1981; 666: 382-393.

34. Pison U, Wright JR, Hawgood S. Specific binding of SPA to rat alveolar macrophages. Am J Physiol 1992; 262 (Lung Cell Mol Physiol 6): L412-L417.

35. Bourbon JR, Chailley-Heu B, Gautier B. The exogenous surfactant Curosurf enhances phosphatidylcholine content in isolated type II cells. Eur Respir J 1997; 10: 914919. 